\title{
Enhanced Behavioral Recovery from Sensorimotor Cortex Lesions after Pyramidotomy in Adult Rats
}

\author{
V.V. Fanardjian, ${ }^{\dagger}$ O.V. Gevorkyan, R.K. Mallina, A.B. Melik-Moussian, and I.B. Meliksetyan \\ L.A. Orbeli Institute of Physiology, National Academy of Sciences of Armenia \\ 22 Orbeli Bros. Str., 375028, Yerevan, Republic of Armenia
}

\section{SUMMARY}

Unilateral transection of the bulbar pyramid, performed before the ablation of the ipsilateral sensorimotor cortex, has been shown to facilitate the recovery of operantly conditioned reflexes and compensatory processes in rats. Such enhanced behavioral recovery was absent when only the sensorimotor cortex was ablated. This phenomenon is explained by the switching of motor activity under the control of the cortico-rubrospinal system. Switching of the descending influences is accomplished through the following loop: cortico-rubral projectionred nucleus-inferior olive-cerebellum-thalamuscerebral cortex. This suggests that a preliminary lesion of the peripheral part of the system, represented by a descending spinal projection, facilitates the recovery processes to develop during the subsequent destruction of its central part.

\section{KEYWORDS}

compensation, operantly conditioned reflexes, switching of descending influences

\section{INTRODUCTION}

Descending pathways in the brain play a critical role in the initiation and control of motor behavior in vertebrates. In the mammalian central nervous system the corticospinal projection is the single largest axonal pathway. The pyramidal tract passing through the brainstem sends a significant number of collaterals to brain stem nuclei (Sarkissian $\&$ Fanardjian, 1984).The pyramidal tract proper, or corticospinal tract, represents the part of pyramidal tract which leaves the brain stem. (Phillips \& Porter, 1977). The extending collaterals are at least the potential pathways of the 'non-pyramidal type' and provide the brain stem structures a copy of cortical motor output. There are numerous points at which impulses generated in the corticospinal neurons may be fed into descending pathways other than the pyramidal, and the distinction between the pyramidal and non-pyramidal systems loses functional significance (Patton \& Amassian, 1960). In rats the collaterals of corticospinal neurons are projecting to the superior colliculus, red nucleus, pontine nuclei, inferior olivary complex and dorsal column nuclei (O'Leary et al., 1988; 1990; Terashima, 1995). Bulbar pyramids therefore mediate only a part of the information coming out of the large pyramidal neurons in the $V$ layer of

\footnotetext{
${ }^{\dagger}$ Corresponding author:

tel: +(3741) 2704 41; Fax: + (3741) 272247

e-mail: fanardjian@neuroscience.am
}

OFREUND \& PETTMAN, U.K., 2000 
sensorimotor cortex of rats. (Leong 1983; Miller, 1987; Miller et al., 1990).

Unilateral pyramidotomy or lesions of the sensorimotor cortex cause motor deficits, varying in severity according to the species. In these operated animals, walking is not abolished permanently but there are striking disturbances in precise movements; for example, demonstration of a reproducible deficit of coordinated walking when the animals cross a narrow beam (Feeney et al., 1982; Goldstein, 1993; 1995). It would be of interest to have a further broad analysis of the precise locomotory abilities in animals with a transected pyramidal tract and lesioned sensorimotor cortex. From this perspective, it is reasonable to study the influence of the above-mentioned damaged structures in animals that are trained for operantly conditioned walking and balancing on a rotating bar.

In addition, in previous investigations (Fanardjian et al., 1999; 2000), we ascertained that preliminary transection of the rubrospinal tract enhances compensatory processes and recovery of instrumental reflexes in rats after the destruction of either the red nucleus or the ventrolateral thalamic nucleus. Such facilitation is considered to be the result of a switching of motor activity onto the corticospinal system by the activation of rubroolivary projections (Kennedy, 1990). Supposedly, the switching effect of the latter is executed in both directions, from the corticospinal system onto the rubrospinal system or vice versa (Lorincz \& Fabre-Thorpe, 1997). This model of correlation between the bulbar pyramid and the sensorimotor cortex appears to be analogous with the previously investigated model, rubrospinal tract-red nucleus (Fanardjian et al., 2000). In the present study, we investigated the influence of preliminary transection of the unilateral bulbar pyramid on instrumental reflexes and compensatory processes on the subsequent ablation of the ipsilateral sensorimotor cortex. Our results show a definite dependence in the severity of motor deficit and the level of operantly conditioned reflexes on the precise location and the extent of lesion in the above-mentioned structures. In addition to this, however, we also noted that transection of the bulbar pyramid in rats, which was proceeded by an ablation of the sensorimotor cortex, facilitates the recovery of motor activity and operantly conditioned reflexes. Such a facilitation was absent when the sensorimotor cortex alone was lesioned.

\section{EXPERIMENTAL PROCEDURES}

Experiments were performed on 2 to 3 months old albino rats weighing 210 to $250 \mathrm{~g}$ each $(n=21)$. All efforts were made to minimize animal suffering and to reduce the number of animals used. All the rats were operantly conditioned to walk and balance on a slowly rotating horizontal bar ( 9 rotations per min). The length and the diameter of the horizontal bar were $30 \mathrm{~cm}$ and 2 $\mathrm{cm}$, respectively. The bar was fixed at a height of $90 \mathrm{~cm}$ above a soft cushion. Before training, each rat was tested for balance ability to hold on the stable horizontal bar for a period of $10 \mathrm{~s}$. If the rat failed the test, it was discarded from the experiment. Conditioning for the reflex of equilibrium was determined as the time spent on the rotating bar. The maximal time of each trial was $5 \mathrm{~min}$. After a resting time of $1 \mathrm{~min}$ on the soft cushion, the trial was repeated; 10 trials constituted a daily session for each rat. The criterion of the execution of a reflex was the rat's ability to balance on the rotating bar for no less than $250 \mathrm{~s}$. During the trial if the rat turned $180^{\circ}$, walked along the bar, or raised toward the partition-wall, then the corresponding trial was not counted as an executed task (Kennedy \& Humphry, 1987). In the process of training, the rats, as a rule, took a comfortable position on the bar.

After the conditioning for a stable equilibrium reflex, the rats were anesthetized using sodium 
pentobarbital (Nembutal, Tallinn) (40 mg/kg i.p.) before performing the surgical procedures. Either a unilateral transection of bulbar pyramid or a unilateral ablation of sensorimotor cortex were performed in various rats. In some animals, both operations were performed consequently on one and the same animal. The unilateral pyramidotomy was performed by a ventral approach. After a midline incision was made in the ventral neck region, the thyroid glands were separated and retracted. The trachea and the esophagus were moved aside gently. The baso-occipital bone covering the pyramids was exposed, and the area rostral to the foramen magnum was removed. Subsequently the pyramids were exposed at the base of the medulla oblongata (Barron, 1934; Z'Graggen et al., 1998).

The pyramid was sectioned through the dura mater unilaterally at the level of caudal medulla oblongata in single or paired transections. Great care was taken to avoid damage to the basilar artery arranged between the pyramids. The trachea, esophagus, and thyroids glands were replaced to their normal position, and the wound was stitched with surgical thread. The surgical procedure associated with the ablation of the sensorimotor cortex was executed by craniotomy which, as a rule, extended $2 \mathrm{~mm}$ rostrally and $3 \mathrm{~mm}$ caudally from the bregma and $4 \mathrm{~mm}$ laterally from the sagittal suture. The cortex underlying the region of craniotomy was removed by gentle suction through a tiny glass pipette until the white matter was visualized (Goldstein, 1993). In some rats, the cortex was removed by a surgical spoon. The sensorimotor cortex was identified on the basis of maps that were composed using previous morphological and physiological investigations (Krieg, 1946; Hall \& Lindholm, 1974; Hicks \& D'Amato, 1977). The described surgical procedures were conducted either before or after the conditioning of equilibrium reflexes in the three following series of experiments:
- Series A. Unilateral pyramidotomy was carried out on rats trained for conditioning of the equilibrium reflex. After the operation, the rats were retrained and after the restoration of the stable reflex, aspiration lesion of the ipsilateral sensorimotor cortex was performed. After the operation, the training sessions and the examination of neurological status continued (Rats A1-A7).

- Series B. Unilateral aspiration lesion of the sensorimotor cortex was performed on rats trained for conditioning reflex. After the operation, the rats were retrained and the neurological status examined (Rats B1-B6).

- Series C. A preliminary ablation of the unilateral sensorimotor cortex was performed in rats. Later, after the recovery of neurological status, the training sessions on the conditioning of equilibrium reflex was performed (Rats $\mathrm{Cl}$ C5). This group of experiments served as the control for series $\mathbf{B}$, in which the dependence of conditioning of instrumental reflexes on the time of removal of sensorimotor cortex was evaluated.

After each operation, the rats were trained or retrained for the equilibrium reflex to study common patterns of dynamic changes in behavior. In parallel, neurological investigations of motor disturbances were also conducted. Grasping reflex of the bar, flexion reflex, withdrawal of paws on pinching, and rectification of the trunk and head position during a fall were examined. The animals were housed under standard conditions of vivarium in groups containing 4 to 5 rats each.

At the end of the experiment, the damaged structures were evaluated morphologically: the lesions were analyzed for their localization, extent, and depth. The experimental animals were killed under a lethal dose of pentobarbital, and the extracted brains were fixed in $10 \%$ neutral formalin. The sections of the cerebral cortex and subcortical 
structures with a thickness of $50 \mu \mathrm{m}$ (one section per 500 ) were stained by Nissl's method, $0.1 \%$ aqueous solution of thionine. For the staining of myelin and determining the size of transection of bulbar pyramid, sections of 40 to $50 \mu \mathrm{m}$ were prepared from the medulla oblongata, which were later placed in $5 \%$ aqueous solution of ferric chloride $\left(\mathrm{FeCl}_{3} \cdot 6 \mathrm{H}_{2} \mathrm{O}\right)$. The sections were then processed by the method of Gomori (1950) to determine the activity of acid phosphatase for modifying the concentration factor of the mediun (Chilingarian, 1980).

Both lesions were performed unilaterally to the left and localized precisely. The boundaries of sensorimotor region of the cerebral cortex were determined according to the map of Hicks \& D'Amato (1977). The localization of bulbar pyramids was determined by the atlas of stereotaxic coordinates in the rats (Paxions \& Watson, 1986).

The Student's t-test was used to determine the extent of the difference in the recovery of motor activity and instrumental reflexes (Pollard, 1977).

\section{RESULTS}

\section{Histological evaluation of the lesions}

The lesions of the cerebral cortex (Fig. 1) were either restricted in the rostrocaudal direction of the hindlimb area in three rats $\left(A_{2}, C_{2}, C_{3}\right)$ or involved the entire sensorimotor region (A4-A7, B1-B4, $\mathrm{C}$, C5) and spread more rostrally (B5, B6, $\left.\mathrm{C}_{1}\right)$, as well as involving more caudal parts of the cerebral cortex (in rats $\mathrm{Al}, \mathrm{A} 3, \mathrm{B5}, \mathrm{Cl}_{1}$ ). The material can be divided into the following three groups based on the depth of lesion:

1. Lesioning of all the layers of the cerebral cortex (Fig. 2).

2. Complete lesioning of all the layers of sensorimotor cortex and the underlying white matter.
3. Lesioning of the sensorimotor cortex and white matter up to region $\mathrm{CA}_{3}$ of the dorsal hippocampus (A6, B3, B4).

Subsequent histological investigation showed the presence of unilateral transection of the bulbar pyramid in all rats under investigation, with minor deviations in the extent of the lesion (Fig. 3). Figure 4 demonstrates clearly labeled myelinated fibres and the exact site of the pyramid's transection. It is necessary to note that the rats in the age group ( 2 to $3 \mathrm{mo}$ ) selected were used to exclude the possibility that the pyramidal fibres could regenerate spontaneously after the medullary transection, as seen in younger rats (Inoue et al., 1998).

\section{Neurological disorders}

The rats were tested for motor disturbances as soon as they recovered from anesthesia. Rats that underwent unilateral pyramidotomy showed the following disturbances. Rats resisted being removed from the cage, and they grasped the mesh with its healthy limbs. The rat, when made to walk on the floor, dragged its affected hind limb. Often the toes of the paralyzed side were misplaced, which made the rat tilt toward the affected side. Two-to-three days later, the rats were seen to walk on their paralyzed toes instead of using the entire extremity. Such disorders of gait disappeared on average 6 to 7 days after pyramidotomy, although the paresis of the affected toes did not completely recover for a long time. When the rat was resting in the cage, the affected limb lay inert and the toes were not flexed but were extended. The rat used its forelimb for washing its face rather than the fore limb digits. The animal was unable to grasp the food with its digits. All these disturbances indicate a clear decrease in the flexor tone of the test side. The disturbances in the motor activity were more apparent when the rat was placed on the rotating 

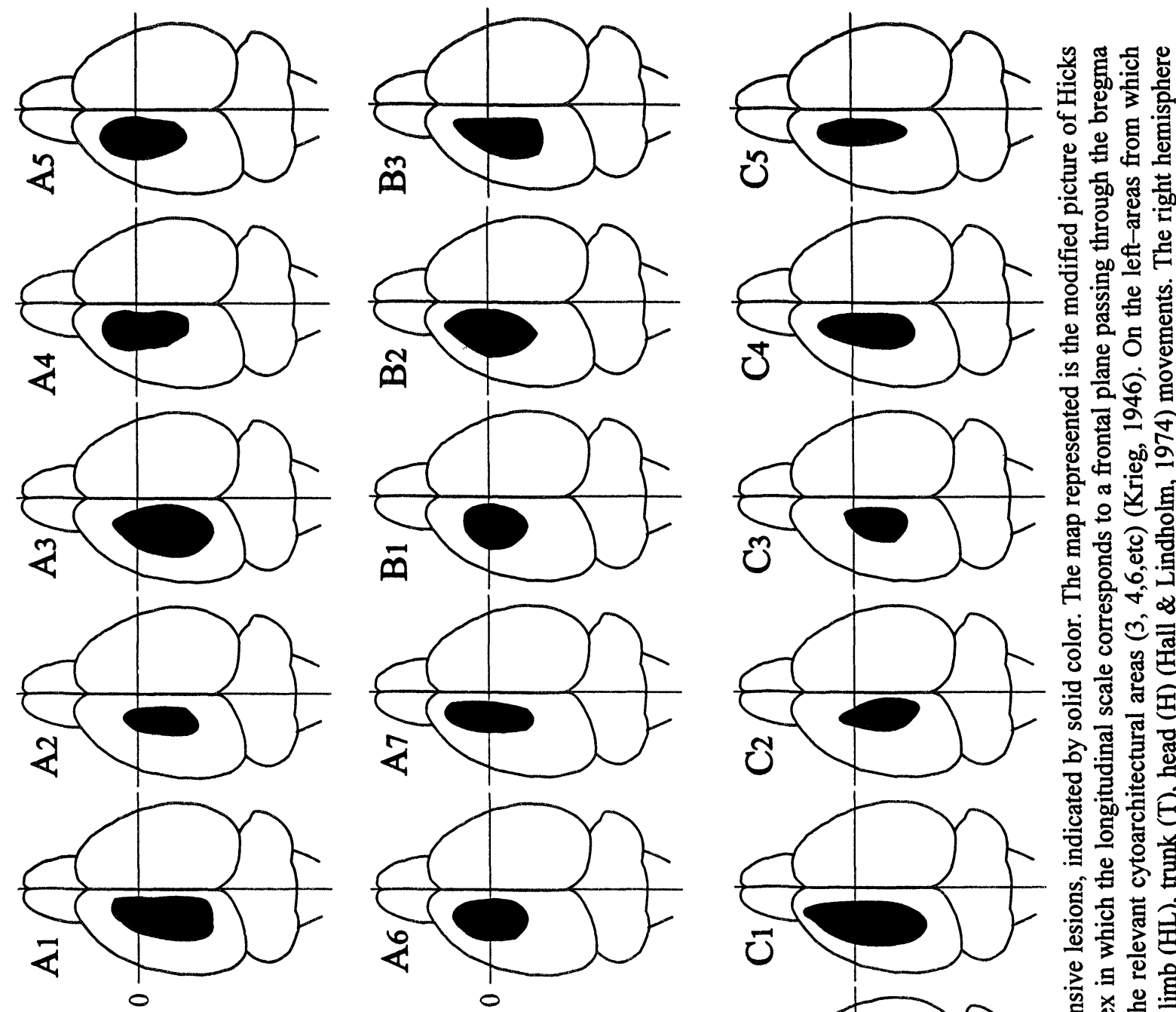

还至点
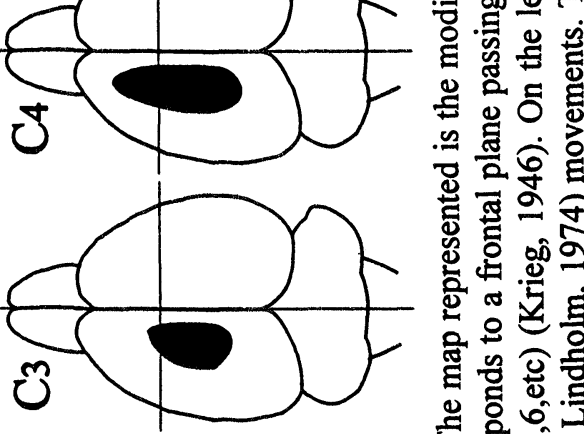

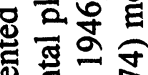

边

递

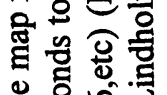

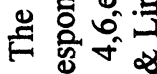

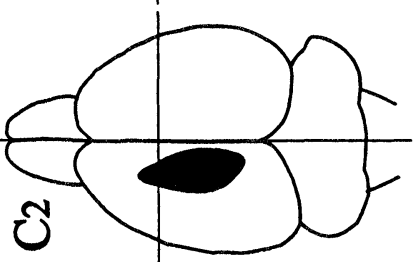

눙

造通完

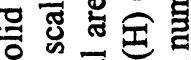
宫䨔焉

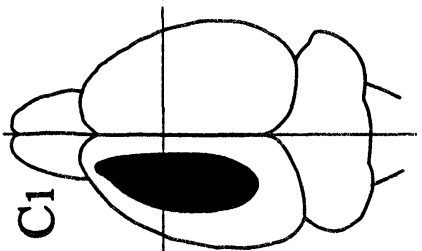

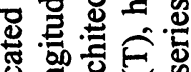
응 总

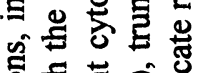

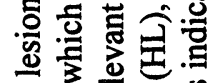
의 은

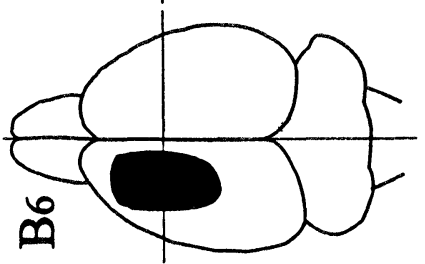

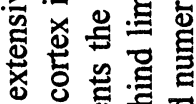

응 형

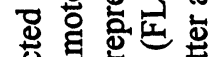
녕

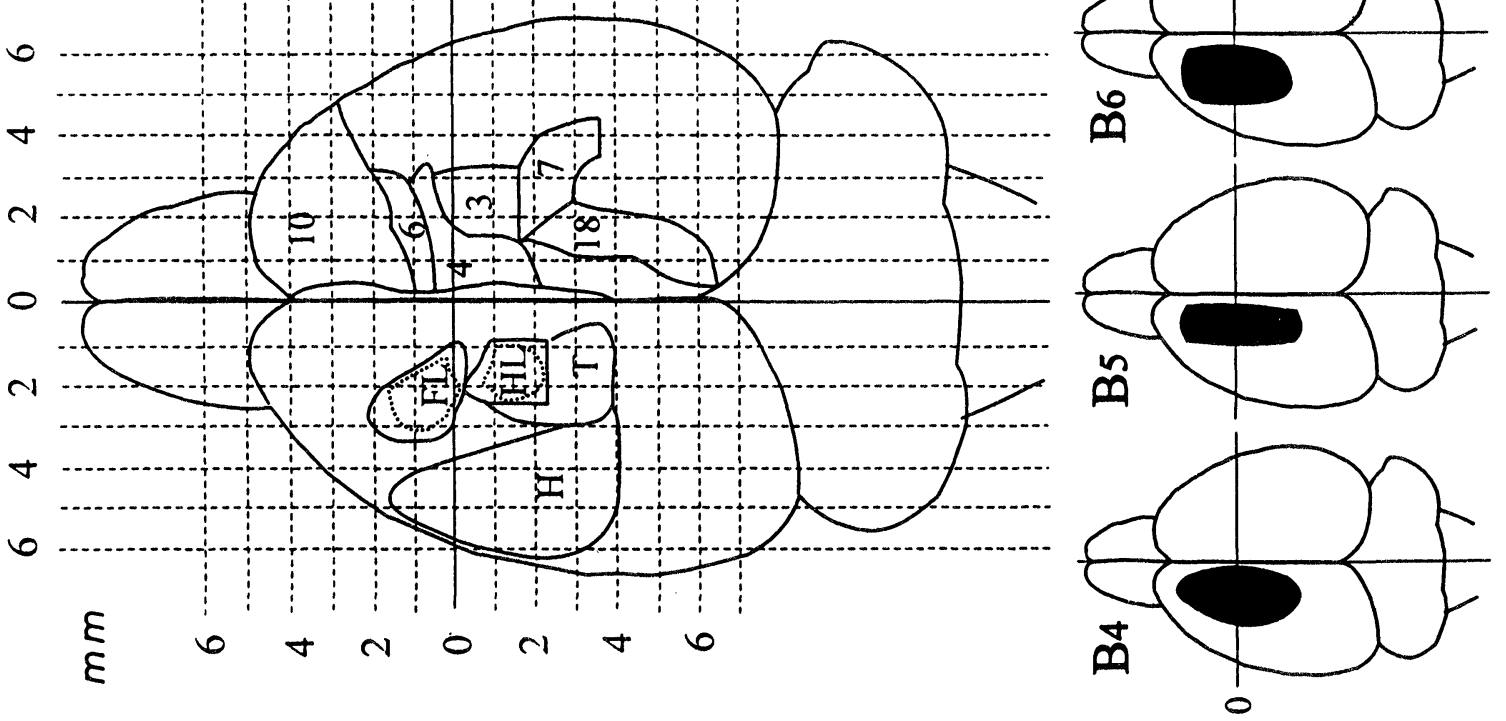

空总营

点合兽焉

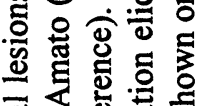

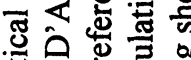

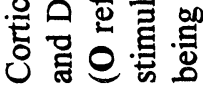




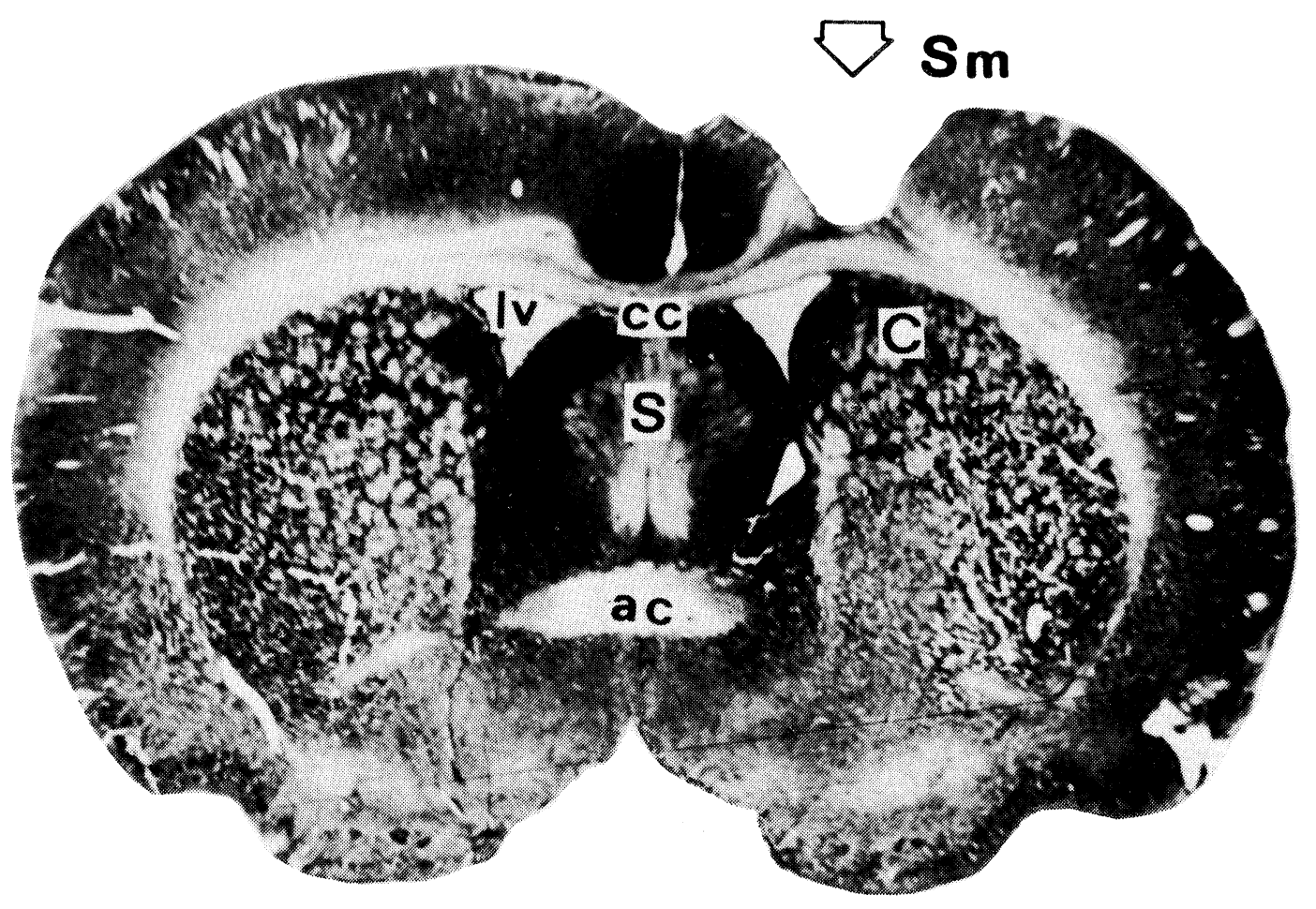

Fig. 2: Microphotograph of the frontal section of the rat cerebral cortex and subcortical structures with the ablation of the cortical sensorimotor area designated by open arrowhead. Section was stained using the Nissl method with thionine. $\times$ 10. Abbreviations: ac-anterior commissure; $\mathrm{C}-\mathrm{n}$. caudatus; cc-corpus callosum; lv-lateral ventricule; S-septum; Sm-sensorimotor cortex..

bar. The grasping reflex of the affected side on the bar was greatly weakened. Although there was a decrease in the flexor tone of the affected side, the rat was able to perform the given task, the only difference being a decreased number of stepping of the affected hind limb, or in many cases the limb initially lay inert on the bar. On the rotating bar, the rats forelimb digits extended out and the extremity was adducted to the medial side. In contrast, the affected hind limb abducted its hind limb away from the body. At the time of balancing the rats hind limb slipped, making the rat turn by b1 $180^{\circ}$ or $360^{\circ}$. These slipping movements were more frequent in number in animals that did not undergo training. All the above changes were also observed after ablation of the sensorimotor cortex, the only difference observed was in the severity of the motor disturbances. Moreover, in the rats with an ablation of sensorimotor cortex, there was a marked tilt to the affected side at the time of balancing and walking on the bar. In these animals, the sensory function of the contralateral side was decreased to some extent. While balancing, the affected hind limb was hanging freely and even touched the freely hanging fore limb of the same side. The severity in the motor disturbances was in direct relation to the extent of damage. This phenomenon was clearly demonstrated in the rats 


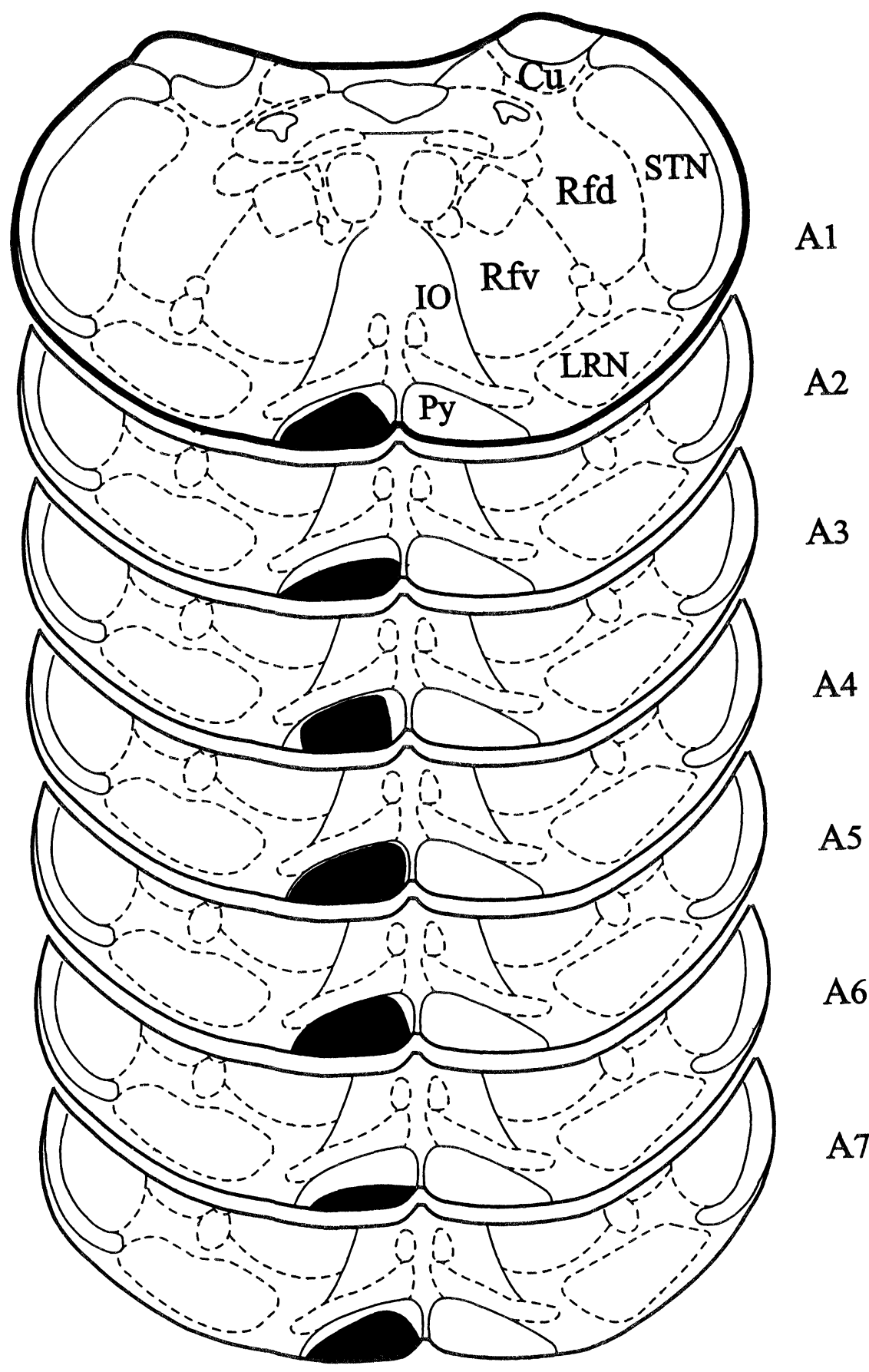

Fig. 3: Extent of pyramidal lesions in rats. The lesions are redrawn by solid color on frontal section at $13.68 \mathrm{~mm}$ caudal from bregma (Paxinos \& Watson, 1986). The right side is being shown on the right. Letter and numerals indicate rat series and number. $\mathrm{Cu}$-cuneate nucleus; IO-inferior olive; LRN -lateral reticular nucleus; Pypyramidal tract; Rfd-medullary reticular field, dorsal; Rfv-medullary reticular field, ventral; STN-spinal trigeminal nucleus. 


\section{TABLE 1}

Dynamics of elaboration of the instrumental reflexes after unilateral transection of the pyramid and ablation of the sensorimotor cortex in adult rats

\begin{tabular}{|l|c|c|}
\hline Treatment group & Mean $( \pm \mathrm{SD})$ no. days to reach criterion & $\mathrm{N}$ \\
\hline \multicolumn{2}{|c|}{$2.5 \pm 1.1$} & 21 \\
\hline \multicolumn{2}{|c|}{ Training before surgery } \\
\hline Transection of pyramid & $3.9 \pm 1.4$ & 7 \\
\hline $\begin{array}{l}\text { Transection of pyramid and subsequent } \\
\text { ablation of the ipsilateral sensorimotor cortex }\end{array}$ & $9.2 \pm 1.8^{*}$ & 5 \\
\hline Ablation of the sensorimotor cortex & $19.0 \pm 5.3^{*}$ & 5 \\
\hline \multicolumn{2}{|c|}{ Training after surgery } \\
\hline Ablation of the sensorimotor cortex & $19.8 \pm 6.4$ & 5 \\
\hline
\end{tabular}

$* \mathrm{p}<0.05$

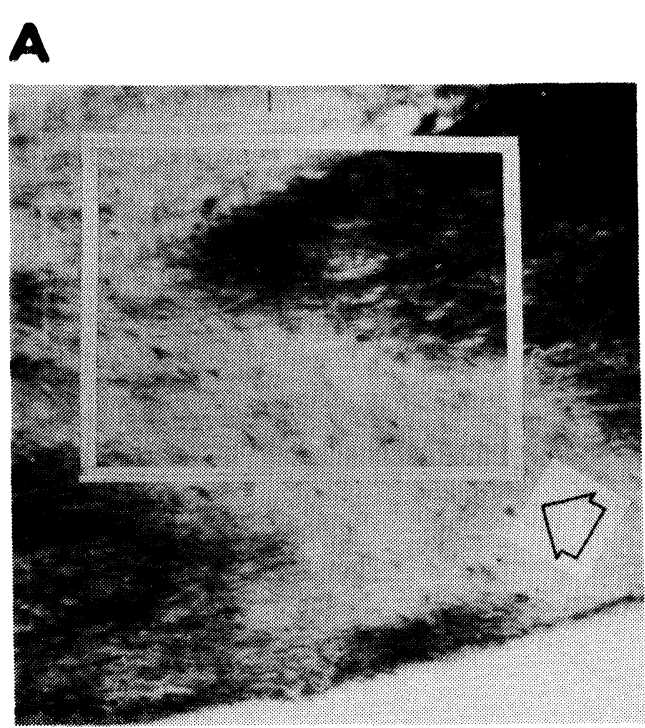

B

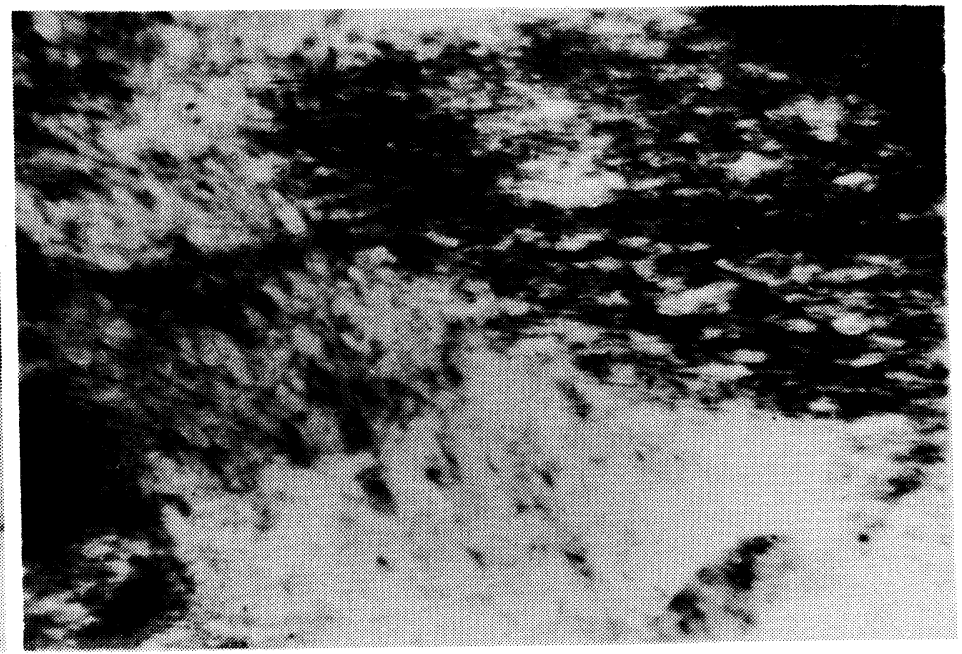

Fig. 4: Microphotographs of longitudinal section of the rat caudal medulla oblongata after unilateral pyramidotomy. (A) The site of lesion is indicated by an open arrowhead. Inset see in B. (B) Inset shows higher magnification of the course of myelinated fibres. Scale bars $=52 \mu \mathrm{m}$ (A), $25 \mu \mathrm{m}$ (B). 
after removal of the sensorimotor cortex. A minor lesion, confined mainly to the hindlimb region (Fig. 1), led to motor disturbances of the hind limb only. After an aspiration lesion of the sensorimotor cortex, the motor disturbances recovered on average 7 days after the operation. The represented periods of recovery in the motor activity after unilateral pyramidotomy and ablation of the sensorimotor cortex in rats agree with those in the literature (Barron, 1934; Goldstein, 1993; 1995). Such disorders as the recovery of the fine movements of the digits were not uncompensated. The recovery of other motor disturbances, however, was faster in rats with a preliminary pyramidatomy. The subsequent removal of the sensorimotor cortex resulted in a quicker recovery of motor distubances.

\section{Operant conditioning}

In naive rats that were operantly conditioned, the defined criterion for stable reflexes was reached on the $2^{\text {nd }}$ to $4^{\text {th }}$ experimental day (mean days $2.5 \pm 1.1 ; \mathrm{SD} ; \mathrm{n}=21$ ) (Table 1). Among the seven rats of series $\mathbf{A}$, the bulbar pyramid was transected, which led to the above mentioned motor disturbances. On the day following the operation, the conditioning of instrumental reflexes resumed and became stable by the $3^{\text {rd }}$ to $7^{\text {th }}$ days (mean days $3.9 \pm 1.3 ; n=7$ ) (Table 1 and Fig. 5, B). In all the animals of this series having stable instrumental reflexes, the sensorimotor cortex was lesioned ipsilateral to the transected pyramid. On the day following the latter surgical procedure, the conditioning for instrumental reflexes resumed and became stable by the $7^{\text {th }}$ to $11^{\text {th }}$ day (mean days $\left.9.2 \pm 1.8 ; n=5\right)$ (Table 1 and Fig. 5, B). There was a relation between the severity of motor disturbances and the rate of conditioning for instrumental reflexes that depended on the extent of the sensorimotor cortex lesion. Thus in rat $\mathrm{A} 2$, there was a stable instrumental reflex on the $6^{\text {th }}$ day after the operation. Subsequent histological analysis showed that the area of forelimb on the sensorimotor cortex was not completely involved in the lesion (Fig. 1). The results of this investigation were discarded during the analysis of the time of development of stable reflexes. Similarly, in rat A6, along with lesioning of the sensorimotor cortex, a wide area involving subcortical structures was damaged. As a result of a deep lesion in rat A6, strong vestibular disturbances hampered the conditioning of instrumental reflexes.

In all the six rats of series $B$, with a conditioned instrumental reflex, the sensorimotor cortex was lesioned unilaterally. After the operation on the second day, the conditioning for instrumental reflexes resumed, which became stable in 5 rats by the $14^{\text {th }}$ to $26^{\text {th }}$ days (mean days 19.0 $\pm 5.3, n=5)($ Table 1 and Fig. 5, A). In rat B4, the instrumental reflex was not stable even on the $55^{\text {th }}$ day after the operation. Histological analysis of this rat showed that along with lesioning of the sensorimotor cortex, the subcortical structures up to the region $\mathrm{CA} 3$ of the dorsal hippocampus were destroyed. Thus, the results of this investigation were not considered during the analysis of the time of elaboration of stable reflexes.

In the 5 rats of series $\mathbf{C}$, there was a preliminary unilateral ablation of sensorimotor cortex, after which the instrumental reflexes were conditioned, which became stable on the $10^{\text {th }}$ to $29^{\text {th }}$ days (mean days 19.8 $\pm 6.4 ; n=5)$ (Table 1 and (Fig. 5, C).

A comparative analysis of the results obtained in series $\mathbf{A}$ and $\mathbf{B}$ showed that a preliminary transection of the medullary pyramid had a clear facilitating influence on the recovery of motor activity and instrumental reflexes after the ablation of the ipsilateral sensorimotor cortex. The difference between the recovery periods of instrumental reflexes after the ablation proceeded 

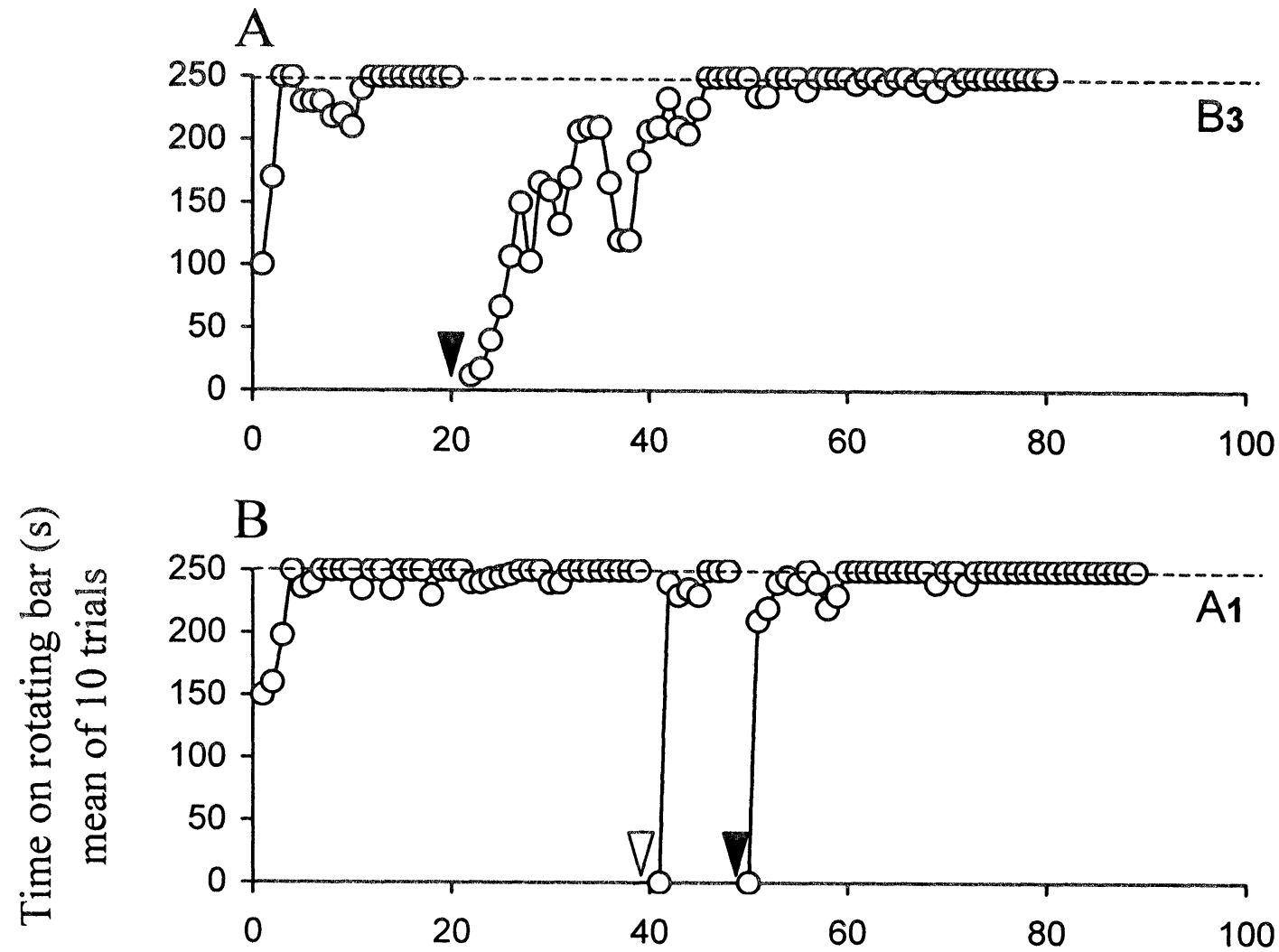

$\mathrm{C}$

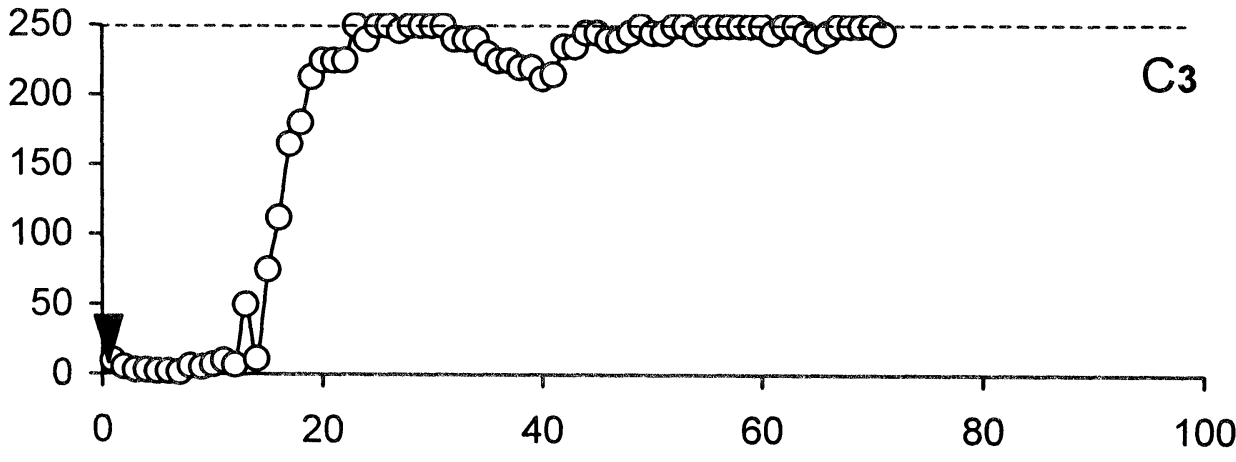

Testing days

Fig. 5: Effects of unilateral transection of the bulbar pyramid and ablation of the ipsilateral sensorimotor cortex on the performance of instrumental reflexes in three rats. The instrumental reflexes were trained before $(A, B)$ or after (C) these lesions. (A, C) Sensorimotor cortex alone was ablated. (B) Sensorimotor cortex was ablated after transection of the pyramid. The progression of reflexes is shown in days (abscissa). The mean value (in seconds) of 10 trials on the rotating bar is plotted for each training day (ordinate). The dashed line is the 250-s criterion level of performance. The open arrowhead designates the day of pyramid transection; the closed arrowhead indicates the day of sensorimotor cortex ablation. Letter and numerals indicate rat series and number. 
by transection of bulbar pyramids was taken as the period of facilitation (compare $19.0 \mathrm{~d}$ and $9.2 \mathrm{~d}$ ) $(p<0.05)$. It is interesting that in the rats of series $C$, in whom there was a preliminary lesion of by transection of bulbar pyramids was taken as the period of facilitation (compare $19.0 \mathrm{~d}$ and $9.2 \mathrm{~d}$ ) $(p<0.05)$. It is interesting that in the rats of series $\mathrm{C}$, in whom there was a preliminary lesion of the sensorimotor cortex followed by conditioning for instrumental reflexes, the instrumental reflexes became stable at 20.6 days, a period close to that of the rats in series $\mathbf{B}$.

\section{DISCUSSION}

The corticospinal and rubrospinal tracts constitute the laterally descending brainstem pathways (Kuypers, 1964). Cerebellar messages can modulate the activity of these tracts through both the motor cortex and the red nucleus. In the cat, cerebellar outputs gain access to the various cortical zones through the ventrolateral and the ventroanterior thalamic nuclei (motor thalamus) (Lorincz \& Fabre-Thorpe, 1997). The cerebellum can also influence the rubrospinal and rubroolivary tracts through its direct projections onto the red nucleus (Massion 1967; Fanardjian \& Sarkisian, 1992). Similarly, the red nucleus receives massive projection from the ipsilateral sensorimotor and parietal cortex (Jeneskog \& Padel, 1983; Fanardjian \& Gorodnov, 1983). Cerebellar and cortical inputs are topographically organized and overlap widely. As a result motor outputs can be modulated by informational convergence from both sources (Alstermark et al., 1981; Jeneskog \& Padel, 1983; Giuffrida et al., 1988). In monkey and cat, the neuronal responses of the motor thalamus and the red nucleus are strictly correlated with motion and, as a rule, start before the onset of movements (Amalric et al., 1983; Martin \& Ghez, 1988; Anderson et al.,
1991; Voneida, 1999). Both the rubrospinal and corticospinal pathways are thus largely under the control of the cerebellum (Miller \& Brooks, 1982; Keifer \& Houk, 1994). Both systems can interact via numerous loops in the cortex, the brainstem, and the spinal levels. Both systems send projections to various levels of the spinal cord (Massion, 1967; Fanardjian \& Sarkissian, 1992).

The corticospinal and rubrospinal axons have been shown to possess very similar branching patterns (Shinoda et al., 1988). The terminals may overlap in the same spinal layers and may synapse on the same neurons (Bayev \& Kostyuk, 1973; Jankowska, 1978); Physiologically, the same effects are also described as originating from the two tracts (Woolsey, 1956). It should be mentioned that in rats, there is no clear separation between the parvocellular and the magnocellular divisions in the red nucleus. Rubrospinal neurons are distributed in the parvo- and magnocellular divisions of the red nucleus along its whole rostrocaudal extent (Shieh et al., 1983; Kennedy, 1990). Moreover, all types of neurons of the red nucleus project onto the spinal cord and inferior olive (Kennedy, 1990). Neurons of both divisions of the red nucleus receive inputs from the cerebral cortex. In fact, the sensorimotor cortex projects to the spinal cord both directly and indirectly via the red nucleus (i.e., a cortico-rubrospinal path). In rats, the rubro-olivary projection contains collaterals of the axons of some rubrospinal neurons (Kennedy, 1987). In monkeys, a comparative analysis of the influences of the descending corticospinal and rubrospinal tracts revealed many similarities in the functional properties of these two motor systems on the regulation of velocity (Hepp-Reymond \& Wiesendanger, 1972; Cheney et al., 1988; Houk et al., 1988), time of involvement, direction (HeppReymond \& Wiesendanger, 1972; Cheney \& Fetz, 1980), and the force of movements (HeppReymond \& Wiesendanger, 1972; Ghez \& Vicario, 
1978; Cheney \& Fetz, 1980). In parallel, the prevailing participation of the corticospinal neurons during the training of animals for new motor tasks (Paillard, 1978) and the activation of rubrospinal neurons during the execution of already learned movements was observed (Massion, 1988). As the movements were learned, their execution become automated under the control of the rubrospinal tract. Supposedly, such a switching function of the rubro-olivary projection acts in both directions; i.e., it can switch from the corticospinal tract to the rubrospinal tract and from the rubrospinal tract to the corticospinal tract (Lorincz \& Fabre-Thorpe, 1997). In cats and rats, lesion studies confirm a considerable duplication between the rubrospinal tract and the corticospinal

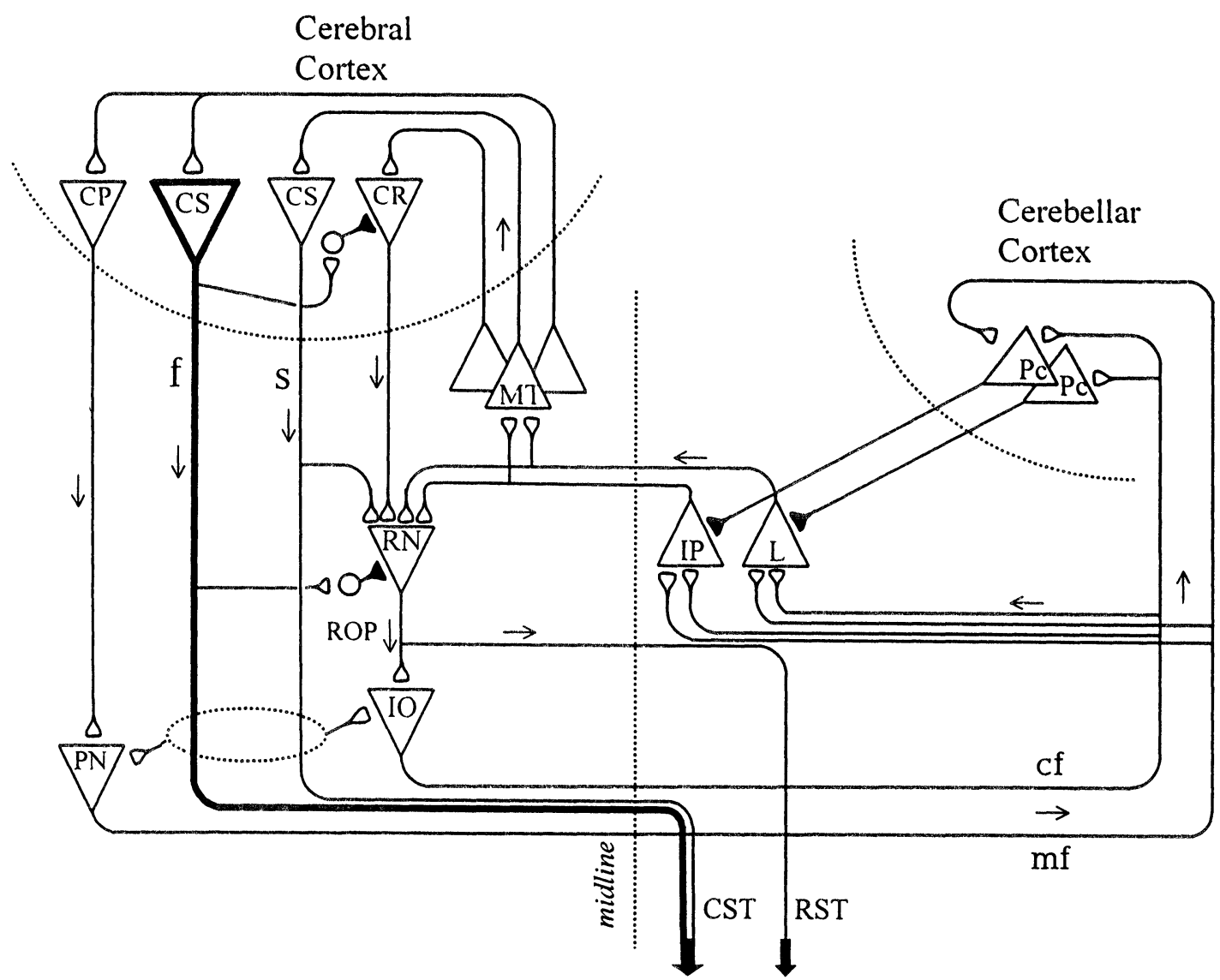

Fig. 6: Diagram of neuronal circuitry of interrelation and substitution of corticispinal and cortico-rubrospinal systems. Corticispinal (CST) projections arise from fast-conducting (CSf) and slow-conducting (CSs) pyramidal tract cells. Cortico-rubral projections arise from coricorubral (CR) cells in the cerebral cortex. CSs and CR are connected monosynaptically with rubrospinal tract (RST) cells of the red nucleus (RN). Neurons of RN receive cerebellar inputs via contralateral n.interpositus (IP) and n. lateralis (L), which are projected also to the cerebral cortex through the motor thalamus (MT). Rubro-olivary projection (ROP) are terminated on the inferior olive (IO), which sent olivo-cerebellar fibres (climbing fibres, $\mathrm{cf}$ ) to Purkinje cells (Pc) and neurons of cerebellar nuclei (IP,L). CSf exert inhibitory influences via interneurons on CR and RST cells. Corticopontine projections (CP) to the pontine nuclei (PN) provides polysynaptic connections from the cerebral cortex to the cerebellum, since efferent neurons of the PN projects onto the cerebellar cortex and its nuclei as mossy fibres $(\mathrm{mf})$. CSf are indicated by thick line. Excitatory and inhibitory projections are indicated by open and filled knobs. Arrows show direction of information flow. 
tract. A deficit produced in one of the two systems is just transitory (Lorincz \& Fabre-Thorpe, 1997), and the functional recovery occurs as a result of the capability of the undamaged system to take control of the motion (Castro, 1972; Martin \& Ghez, 1988; 1991; Levesque \& Fabre-Thorpe, 1990; Martin et al., 1993). In case of damage to both systems, a severe and persisting deficit was produced that either did not recover at all or recovered only after a long period (Lawrence \& Kuypers, 1968; Alstermark et al., 1981).

Our experiments show that a preliminary unilateral transection of the bulbar pyramid accelerated compensatory processes and operantly conditioning following lesion of the ipsilateral sensorimotor cortex in the rats with learned instrumental reflexes in equilibrium. Such acceleration was absent when the sensorimotor cortex was lesioned alone. A pattern similar to that of a lesioned red nucleus and rubrospinal tract develops. Transection of the rubrospinal tract before lesion of the red nucleus has been shown to facilitate the recovery of operantly conditioned reflexes and motor activity. Lesion of the red nucleus alone, however, not preceded by transection of the rubrospinal tract, leads to a prolonged disturbance of motor activity and operantly conditioned reflexes (Kennedy \& Humphry, 1987; Fanardjian et al., 1999; 2000) According to the proposed hypothesis, a quick recovery of motor activity after the transection of rubrospinal tract is a consequence of the activation of the rubro-olivary projection, leading to switching of motor activity under the control of the corticospinal tract (Kennedy, 1990). This switching is accomplished through the participation of the following loop: the inferior olive-cerebellumthalamus-cerebral cortex (Fig. 6). The general property for the model mentioned and that presented in this paper is that a preliminary lesion of a peripheral part of a system, represented by a descending spinal projection, facilitates the recovery processes to be developed during the subsequent destruction of the central part

Corticospinal tract cells receive cerebellar influences through the cerebello-thalamo-cortical relay. The cerebellar influences reaching the cerebral cortex cover a region wider than the area of origin of the corticospinal projections. In parallel, the cerebellum receives the mossy fiber inputs from all over the cerebral cortex. Clearly, the cerebrocerebellar communication loop not only assists the corticospinal tract but also serves a wide variety of cerebral cortical functions (Ito, 1984).

The red nucleus receives massive monosynaptic excitatory projections from the cerebral cortex. The slow-conducting pyramidal tract fibers and cortico-rubral fibers induce the dendritic EPSPs (Tsukahara \& Kosaka, 1968). The fast-conducting pyramidal tract neurons via axon collaterals produce IPSPs in the red nuclear cells with a disynaptic pathway through interneurons within the red nucleus. It is important to note that the fastconducting pyramidal tract neurons also have an inhibitory influence via axon collaterals on the cortico-rubral neurons (Tsukahara et al., 1968). Therefore, the cortico-rubrospinal path can be inhibited at two levels: the cerebral cortex and the red nucleus. Thus, in a normally functioning brain, a switching mechanism is proposed according to which the cortico-rubrospinal system is silenced by inhibition at the level of both the red nucleus and the cerebral cortex when the fast-conducting pyramidal tract cells are activated (Fig. 6). These inhibitory effects are weakened after the completion of training for a motor activity under the control of the cortico-rubrospinal system. In the case of the lesioning of the corticospinal system, the corticorubrospinal system receives a greater volume of freedom, switching for the compensation of the effects of the pyramidal tract. A switching mechanism from the corticospinal to the corticorubrospinal system, acting under normal conditions during the transfer of a newly conditioned movement into an automated regime under the control of the 
cortico-rubrospinal systems, seems to be one of the key events in the compensation of a deficit that is produced by the lesioning of the pyramidal tract.

Along with this switching mechanism, a major role in the compensation of a pyramidal deficit is attributed to the cerebellorubral systems. Once through the cerebellar cortex, the signals produced in the red nucleus during movement have little sensory control, but instead are related to the parameters of movement. These findings support the notion that signals in the red nucleus are not generated by continuous feedback from the periphery, but rather reproduced by the central motor programs (Keifer \& Houk, 1994).

Transection of the medullary pyramid should create error signals going to the cerebral cortex and cerebellum, and the corrective signals would descend to the disrupted corticospinal tracts and to the rubro-olivary projection through which the inferior olive and the cerebellum and later the rubrospinal tract are involved (Kennedy, 1990). Along with this, the inferior olive, which receives direct inputs from corticospinal tract, is deprived of this descending cortical information or the latter is greatly weakened.

In addition, indirect evidence points to the switching of motor control from the corticospinal system to the cortico-rubrospinal system during motor learning. In the case of instrumental feeding reflexes in cats, it was shown that conditioning is impossible after a preliminary destruction of the ventrolateral nucleus of the thalamus (which presumably had interrupted the cerebello-cortical pathway), but if the reflex is conditioned, it persists even after the destruction of the ventrolateral nucleus of the thalamus (Fabre \& Buser, 1980).

Other data has shown that in monkeys, cooling or damage to the pyramidal tract (Hepp-Reymond \& Wiesendanger, 1972; Miller \& Brooks, 1982) did not have a significant influence on the reaction time in motor trials. Enough evidence exists to propose that these switchings are determined by the action of the cerebellar control system, which remains effective for the cortico-rubrospinal system, even if is disconnected from the cortico-corticospinal system (Ito, 1984). Nevertheless, along with the above-mentioned, the involvement of other mechanisms in the compensation of cortical deficit is not excluded. Among them is the possible activation of cortico-cortical and interhemispheric connections. Additional compensation could be mediated by the medial descending systems (for example, reticulospinal, vestibulospinal, tectospinal). Plasticity may also occur in sensory systems (Thallmair et al., 1998) because the cortico-spinal tract modulates sensory information (Endo et al., 1973).

\section{ACKOWLEDGMENTS}

The authors wish to thank Prof. Kh.H. Nahapetian for his kind assistance in the surgical procedures and Dr. L.V. Nurbekyan for technical help.

\section{REFERENCES}

Alstermark B, Lundberg A, Norrsell U, Sybirska E. Integration in descending motor pathways controlling the forelimb in the cat. Exp Brain Res 1981; 42: 299-318.

Amalric M, Conde' H, Dormont JF, Farin D, Schmied A. Cat red nucleus changes of activity during the motor initiation in a reaction time task. Exp Brain Res 1983; 52: 210-218.

Anderson ME, Turner RS. Activity of neurons in cerebellar-receiving and pallidal-receiving areas of the thalamus of the behaving monkey. J Neurophysiol 1991; 66: 879-893.

Barron DH. The results of unilateral pyramidal section in the rat. J Comp Neurol 1934; 60: 45-56.

Bayev KV, Kostyuk PG. Convergences of cortico- and rubrospinal influences on the cervical cord interneurons in the cat. Brain Res 1973; 52: 159-172. 
Castro AJ. Motor performance in rats. The effects of pyramidal tract section. Brain Res 1972 ; 44: 313323.

Cheney PD, Fetz EE. Functional classes of primate corticomotoneuronal cells and their relation to active force. J Neurophysiol 1980; 44: 773-791.

Cheney PD, Mewes K,Fetz EE. Encoding of motor parameters by corticomotoneuronal (CM) and rubromotoneuronal (RM) cell producing postspike facilitation of forelimb muscules in the behaving monkey. Behav Brain Res 1988; 28: 181-191.

Chilingarian AM. The inorganic phosphor and morphohistochemical investigation of cell structures. In: Baklavadjian OG, ed, Central and Peripheral Mechanisms of Autonomic Nervous System. Yerevan: Academic Press, 1980: 218-220 (in Russian)

Endo K, Araki T, Yagi N. The distribution and pattern of axon branching of pyramidal tract cells. Brain Res 1973; 57: 484-491.

Fabre M, Buser P. Structures involved in acquisition and performance of visually guided movements in the cat. Acta Neurobiol Exp 1980; 40: 95-116.

Fanardjian VV, Gorodnov VL. Electrophysiological properties of cortical inputs of rubrospinal neurons Neurosci Lett 1983; 40: 151-168.

Fanardjian VV, Papoyan EV, Hovhannisyan EA, MelikMoussian AB, Gevorkyan OV, Pogossian VI. The role of some brain structures in the switching of the descending influences in operantly conditioned rats. Neuroscience 2000; 98: 385-395.

Fanardjian VV, Papoyan EV, Pogossian VI, Gevorkyan OV. Comparison of the effects of electrolytic and chemical destruction of the red nucleus on the compensatory capacity of rats with rubrospinal tract lesions. Neural Plast 1999; 6: 123-131.

Fanardjian VV, Sarkissian JS. Neuronal Mechanisms of the Red Nucleus. Moscow, Russia: Nauka 1992 (in Russian).

Feeney DM, Gonzalez A, Law WD. Amphetamine haloperidol and experience interact to affect the rate of recovery after motor cortex injury. Science 1982; 217: 855-857.

Ghez C, Vicario D. Discharge of red nucleus neurons during voluntary muscle contraction: Activity patterns and correlations with isometric force. $J$ Physiol (Paris) 1978; 74: 283-285.

Giuffrida R, Palmeri A, Raffaele R, Ricca G, Sapienza $S$. Convergence pattern of cortical and interposital influences on rubro-spinal neurons of the cat. Behav Brain Res 1988; 28: 113-116.

Goldstein LB. Rapid reliable measurement of lesion parameters for studies of motor recovery after sensorimotor cortex injury in the rat. $J$ Neurosci Meth 1993; 48: 35-42.

Goldstein LB. Right vs. left sensorimotor cortex suction-ablation in the rat: No difference in beamwalking recovery. Brain Res 1995; 674: 167-170.

Gomori G. An improved histochemical technic for acid phosphatase. Stain Technol 1950; 25: 81-85.

Hall RD, Lindholm EP. Organization of motor and somatosensory neocortex in the albino rat. Brain Res 1974; 66: 23-38.

Hepp-Reymond MC, Wiesendanger M. Unilateral pyramidotomy in monkeys: Effect on force and speed of a conditioned precision grip. Brain Res 1972; 36: 117-131.

Hicks SP, D'Amato CJ. Locating corticispinal neurons by retrograde axonal transport of horseradish peroxidase. Exp Neurol 1977; 56: 410-420.

Houk JC, Gibson AR, Harvey CF, Kennedy PR, van Kan P. Activity of primate magnocellular red nucleus related to hand and finger movements. Behav Brain Res 1988; 28: 201-206.

Inoue T, Kawaguchi S, Kurisu K. Spontaneous regeneration of the pyramidal tract after transection in young rats. Neurosci Lett 1998; 247: 151-154.

Ito M. The Cerebellum and Neural Control. New York, NY, USA: Raven Press, 1984

Jankowska E. Some problems of projections and actions of cortico- and rubrospinal fibres. J Physiol (Paris) 1978; 74: 209-214.

Jeneskog T, Padel Y. Cerebral cortical areas of origin of excitation and inhibition of rubrospinal cells in the cat. Exp Brain Res 1983; 50: 309-320.

Keifer J, Houk JC. Motor function of the cerebellorubrospinal system. Physiol Rev 1994; 74: 509-542.

Kennedy PR. Light labelling of red nucleus neurons following an injection of peroxidase-conjugated wheat germ agglutinin into the inferior olivary nucleus of the rat. Neurosci Lett 1987; 74: 262-268.

Kennedy PR. Corticospinal, rubrospinal and rubroolivary projections: a unifying hypothesis. Trends Neurosci 1990; 13: 474-479.

Kennedy PR, Humphry DR. The compensatory role of the parvocellular division of the red nucleus in operantly conditioned rats. Neurosci Res 1987; 5: 39-62. 
Krieg WJS. Connections of the cerebral cortex. 1. The albino rat.A. Topography of the cortical areas. $\mathrm{J}$ Comp Neurol 1946; 84: 221-275.

Kuypers HGJM. The descending pathways to the spinal cord, their anatomy and function. In: Eccles JC, Schade JAPAN, eds, Organization of the Spinal Cord, Prog Brain Res Vol. 11. Amsterdam, London, New York: Elsevier, 1964; 178-202.

Lawrence DG, Kuypers HGJM. The functional organization of the motor system in the monkey: I. The effects of bilateral pyramidal lesions. Brain 1968; 91: 1-14.

Leong SK. Localizing the corticospinal neurons in neonatal, developing and mature albino rat. Brain Res 1983; 265: 1-9.

Levesque F, Fabre-Thorpe M. Motor deficit induced by red nucleus lesion: Reappraisal using kainic acid destructions. Exp Brain Res 1990; 81: 191198.

Lorincz E, Fabre-Thorpe M. Effects of pairing red nucleus and motor thalamus lesions on reaching toward moving targets in cats. Behav Neurosci 1997; 111: 892-907.

Martin JH, Cooper SE, Ghez C. Differential effects of local inactivation within motor cortex and red nucleus on performance of an elbow task in the cat. Exp Brain Res 1993; 94: 418-428.

Martin JH, Ghez C. Red nucleus and motor cortex: Parallel motor systems for the initiation and control of skilled movement. Behav Brain Res 1988; 28: 217-223.

Martin JH, Ghez C. Task-related coding of stimulus and response in cat red nucleus. Exp Brain Res $1991 ; 85$ : 373-388.

Massion J. Mammalian red nucleus. Physiol Rev 1967; 47: 383-436.

Massion J. Red nucleus, past and future. Behav Brain Res 1988; $28: 1-8$.

Miller AD, Brooks VB. Parallel pathways for movement initiation in monkeys Exp Brain Res 1982; 45: 328-332.

Miller MW. The origin of corticospinal projection neurons in rat. Exp Brain Res 1987; 67: 339-351.

Miller MW, Chiaia NL, Rhoades RW. Intracellular recording and injection study of corticospinal neurons in the rat somatosensory cortex: Effect of prenatal exposure to ethanol. J Comp Neurol 1990; 297: 91-105.

O'Leary DDM, Bicknese AR, De Carlos JA, Heffner CD, Koester SE, Kutka LJ, Terashima T. Target selection by cortical axons: Alternative mechanisms to establish axonal connections in the developing brain. Cold Spring Harbor Symp Quant Biol 1990; 50: 453-468.

O'Leary DDM, Terashima T. Cortical axons branch multiple subcortical targets by interstitial axon budding: Implications for target recognition and "waiting periods". Neuron 1988; 1: 901-910.

Paillard J. The pyramidal tract: Two millions fibres in search of the function. J Physiol (Paris) 1978; 74: 115-162.

Patton HD, Amassian VE. The pyramidal tract: Its excitation and functions. In: Field $J$, Magoun HW, Hall VE, eds, Handbook of Physiology, Neuro-physiology, sec I, vol II, Washington, DC, USA: American Physiological Society, 1960; 837-861.

Paxinos G, Watson Ch. The Rat Brain in Stereotaxic Coordinates. $2^{\text {nd }}$ ed. Sydney, Australia: Academic Press, 1986.

Phillips CG, Porter R. Corticospinal Neurons. Their Role in Movement. London, New York, San Francisco: Academic Press, 1977; 1-450.

Pollard JH. Handbook of Numerical and Statistical Techniques. Cambridge, London, New York, Melbourne: Cambridge University Press, 1977.

Sarkissian JS, Fanardjian VV. Distribution and peculiarities of axon collateral branching of rubrospinal neurones in brain stem structures. Neuroscience 1984; 12: 803-815.

Shieh JY, Leong SK, Wong WC. Origin of the rubrospinal tract in neonatal, developing, and mature rats. J Comp Neurol 1983; 214: 79-86.

Shinoda Y, Futami T, Mitoma H, Yokota J. Morphology of single neurones in the cerebellorubrospinal system. Behav Brain Res 1988; 28: 59-64.

Terashima T. Anatomy, development and lesioninduced plasticity of rodent corticospinal tract. Neurosci Res 1995; 22: 139-161.

Thallmair M, Metz GAS, Z'Graggen WJ, Raineteau O, Kartji GL,Schwab ME. Neurite growth inhibition restricts plasticity and functional recovery following corticospinal tract lesions. Nature Neurosci 1998; 1: 124-131.

Tsukahara N, Fuller DRG, Brooks VB. Collateral pyramidal influences on the corticospinal system. J Neurophysiol 1968; 31: 467-484.

Tsukahara N, Kosaka $\mathrm{K}$. The mode of cerebral excitation of red nucleus neurons Exp Brain Res 1968; 5: 102-117. 
Voneida TJ. The effect of rubrospinal tractotomy on a conditioned limb response in the cat. Behav Brain Res 1999; 105: 151-162.

Woolsey CN. Organization of somatic, sensory and motor areas of the cerebral cortex. In: Harlow HF, Woolsey CN, eds, Biological and Biochemical Basis of Behavior, Madison, Wisconsin, USA:
University of Wisconsin Press, 1956; 63-81.

Z'Graggen WJ, Metz GAS, Kartje GL, Thallmair M, Schwab ME. Functional recovery and enhanced corticofugal plasticity after unilateral pyramidal tract lesion and blockade of myelin-associated neurite growth inhibitors in adult rats. J Neurosci 1998; 18: 4744-4757. 

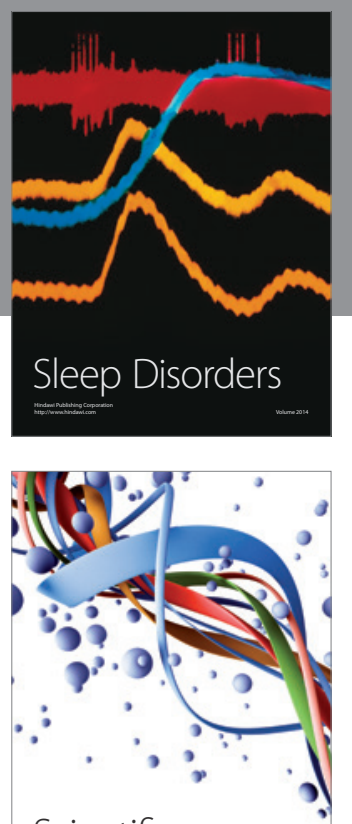

Scientifica
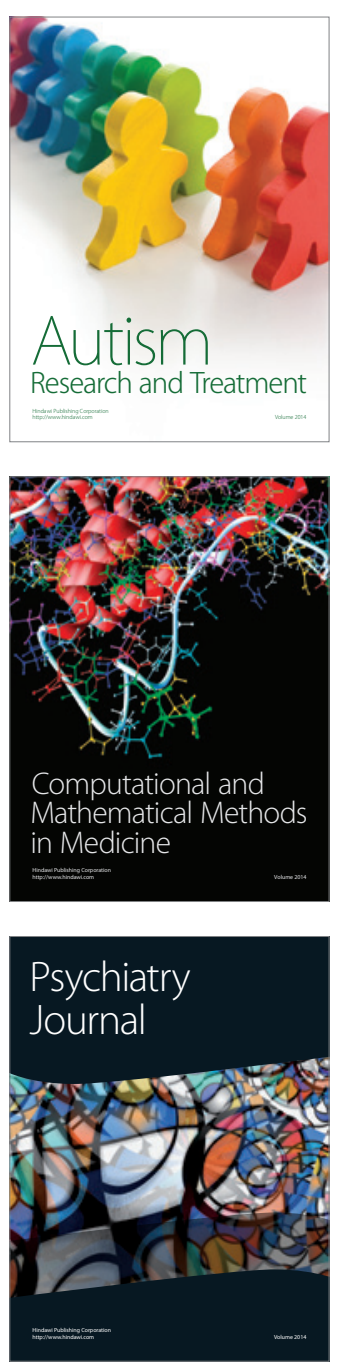
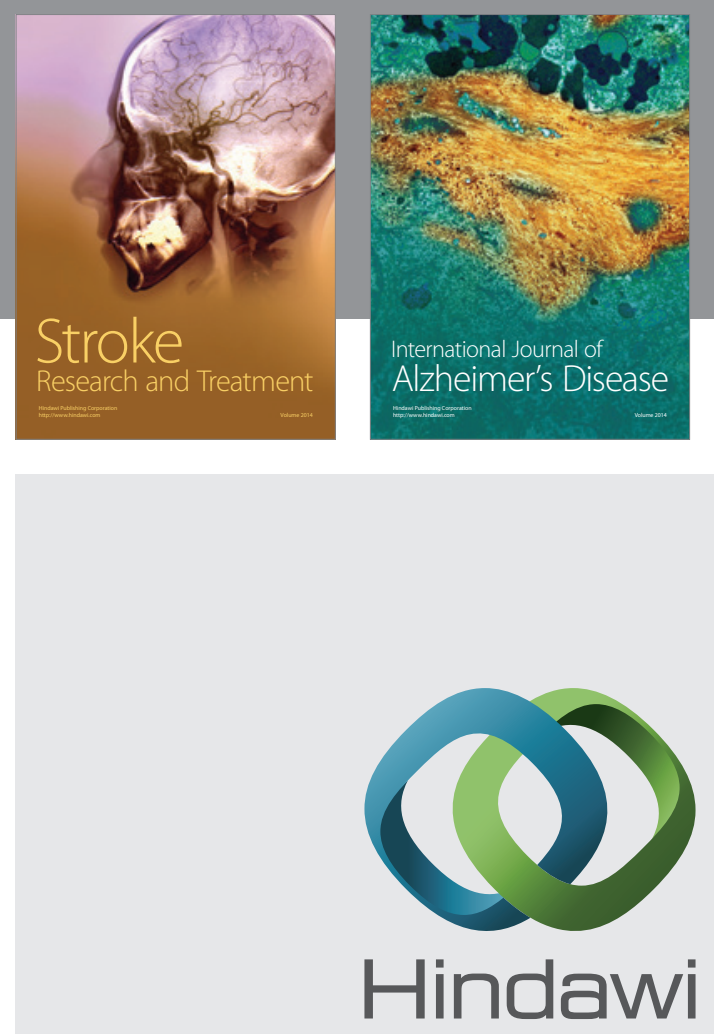

Submit your manuscripts at

http://www.hindawi.com
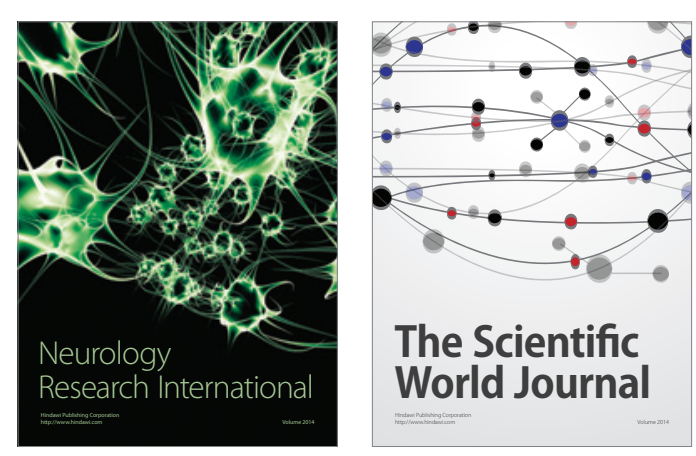

The Scientific World Journal

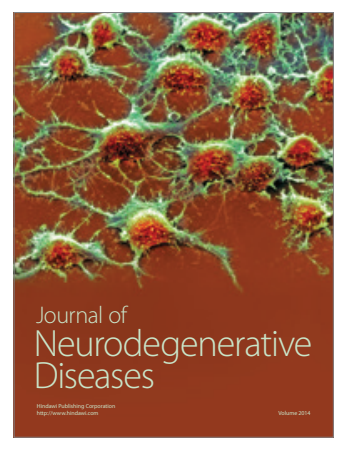

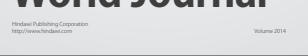

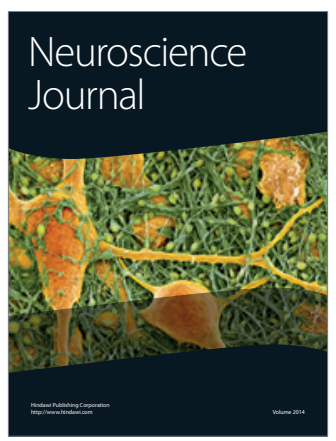

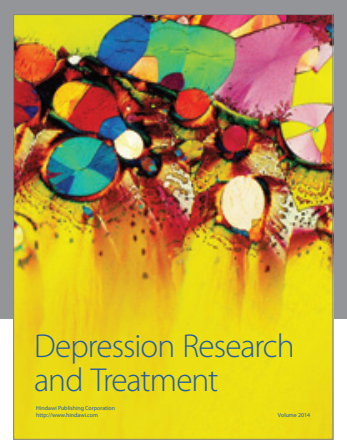
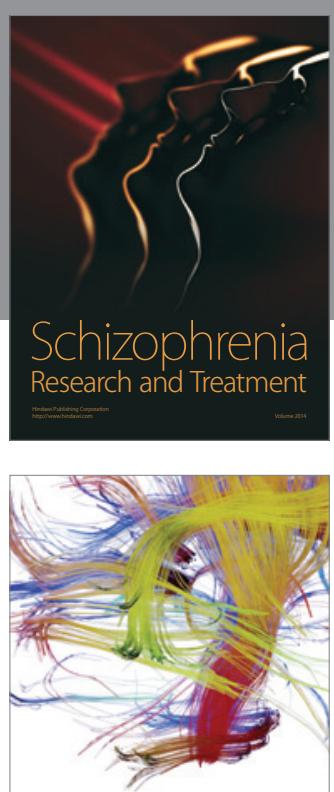

Brain Science

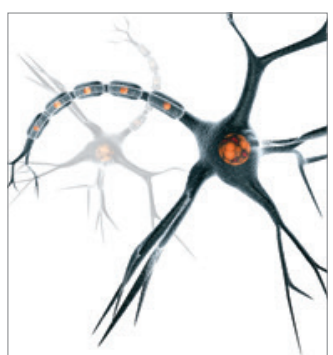

Neural Plasticity
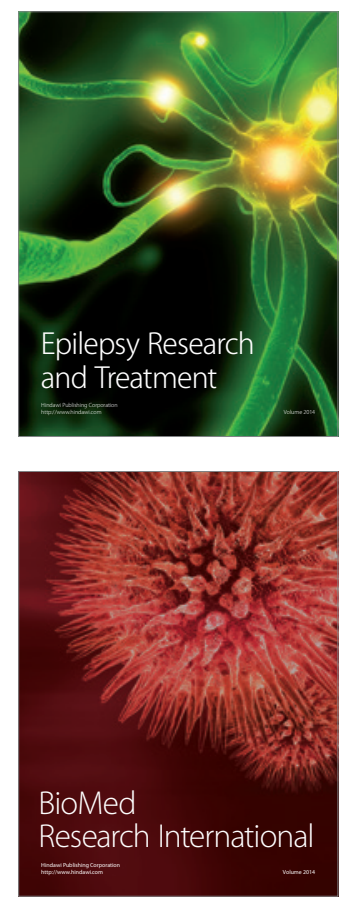

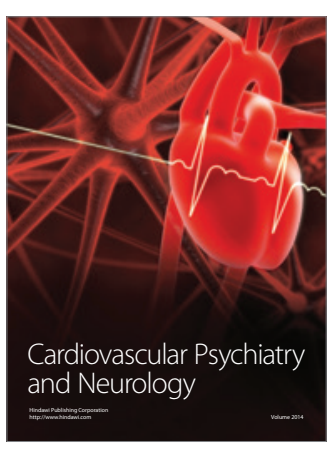

Parkinson's

Disease
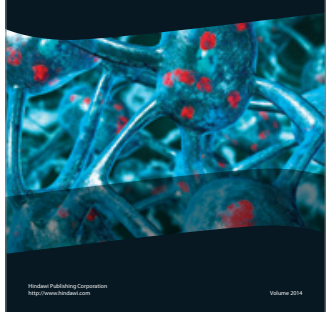